\title{
ENADE 2005 E 2008: DESEMPENHO DOS ESTUDANTES DE BIOLOGIA DE INSTITUIÇÕES DE EDUCAÇÃO SUPERIOR ESTADUAIS E MUNICIPAIS DE SÃO PAULO*
}

\section{Enade 2005 and 2008: performance of Biology students of state and municipal higher education institutions in São Paulo}

Angelo Luiz Cortelazzo ${ }^{1}$ • Viktória Kövesdy Ribeiro ${ }^{2}$

\begin{abstract}
Resumo: Os cursos de Biologia tiveram seus estudantes avaliados no período de 2000 a 2003 por meio do Exame Nacional de Cursos, seguindo-se, a partir de 2005, pela avaliação trienal e amostral do Exame Nacional de Desempenho de Estudantes (Enade), nos termos propostos pela legislação federal, que implantou o Sistema Nacional de Avaliação do Ensino Superior (Sinaes). O presente trabalho analisou a participação dos egressos de cursos de Biologia de escolas estaduais e municipais de São Paulo no Enade de 2005 e de 2008, comparando o desempenho das instituições envolvidas em função: de sua natureza jurídica, da duração de seus cursos e de sua adequação à proposição curricular do Conselho Federal de Biologia.
\end{abstract}

Palavras-chave: Avaliação. Estudantes. Ensino de biologia. Ensino Superior. Enade. Exame Nacional de Desempenho de Estudantes. Governo federal.

\begin{abstract}
Students of Biology courses were evaluated from 2000 to 2003 by the National Courses Assessment exams, followed, from 2005, by the National Examination of Student Performance (Enade), according to the terms of the Federal Legislation, which established the National Assessment System of Higher Education (SINAES). The present study evaluates the Biology course graduates from state and municipal schools in the state of São Paulo, using the Enade exams of 2005 and 2008. This study made comparisons of the performance of these institutions, taking into account their legal status, the duration of their courses and the adequacy of their curriculum, according to the propositions of the Federal Council of Biology.
\end{abstract}

Keywords: Evaluation. Students. Higher education. Biology teaching. Enade. National Examination of Student Performance. Federal government.

\footnotetext{
* Parte da tese de doutorado de V. K. Ribeiro. Part of the doctoral thesis of V. K. Ribeiro.

${ }^{1}$ Instituto de Biologia, Universidade Estadual de Campinas (Unicamp), Departamento de Anatomia, Biologia Celular, Fisiologia e Biofísica. Caixa postal 6109, CEP 13087-970, Campinas, SP, Brasil. Email:

<angelo@unicamp.br>

${ }^{2}$ Programa de Pós-Graduação em Biologia Celular e Estrutural, Universidade Estadual de Campinas

(Unicamp), Campinas, SP, Brasil.
} 


\section{Introdução}

Toda avaliação tem uma dimensão técnica, ética e política. Não se pode desconhecer a sua força transformadora, ou seja, seu papel no estabelecimento de novas configurações para o sistema educacional e, com isto, para a sociedade como um todo. Segundo Gatti (2000, p. 95), "avaliações são processos que devem gerar estímulo, servir de alavanca, servir à mudança e à transformação e não serem utilizados para rebaixamento de autoestima, seletividade, punição, diminuição de valia". Ristoff (2003) enumera treze diversas definições de avaliação, de diferentes autores, passando por aquelas mais diretamente ligadas aos objetivos e metas a serem alcançados até aquelas que envolvem seu papel social, sistemático e parte do processo de análise do projeto pedagógico institucional.

Deve-se destacar que, em uma concepção mais social, a avaliação instaura a reflexão e o questionamento, produzindo sentidos, redirecionamentos e reforços, e tem, assim, um papel sistemático e processual. Por outro lado, pode servir exclusivamente como controle e regulação, prescindindo de qualquer exercício reflexivo e de interrogação, reduzindo-se apenas a um conjunto de medições (DIAS SOBRINHO; RISTOFF, 2003).

Segundo Libâneo (1999), uma avaliação diagnóstica, ao menos em princípio, não objetiva classificar, mas, sobretudo, analisar o processo de construção do conhecimento de um aluno em vias de conquistar um novo nível. É, pois, prospectiva, porque aponta possibilidades futuras, mostrando o que os alunos são capazes de resolver sozinhos e o que podem resolver com a ajuda de professores, companheiros, livros, materiais didáticos etc.

Em termos nacionais, a Lei no 9.394/96, Lei de Diretrizes Nacionais da Educação Nacional (LDB) (BRASIL, 1996), dá destaque para o fato de que deve haver a garantia de um padrão da qualidade do ensino (Art. $3^{\circ}$, IX), a ser assegurado por processo nacional de avaliação das Instituições de Educação Superior (IES), com a cooperação dos sistemas que tiverem responsabilidade sobre este nível de ensino (Art. $9^{\circ}$, VIII). Desse modo, fica clara e explícita a necessidade de ser estabelecido um sistema avaliativo para a Educação Superior, produto do avanço de outras práticas avaliativas que remontam à década de 1950 (RANIERI, 2000).

Efetivamente, os primeiros passos consolidados para um sistema nacional de avaliação passam pela estrutura e sistemática montadas pela Coordenadoria de Aperfeiçoamento de Pessoal do Ensino Superior (Capes), ligada ao Ministério da Educação (MEC), e que desenvolve, há mais de trinta anos, um complexo sistema de análise dos cursos e programas de pós-graduação (COORDENADORIA DE APERFEIÇOAMENTO DE PESSOAL DO ENSINO SUPERIOR, 2010), contribuindo para o atual estágio de qualidade alcançado pelos mestrados e doutorados recomendados pelo seu sistema de avaliação, que conta com reconhecimento internacional. Na graduação, os sistemas de avaliação vêm se desenvolvendo de forma menos sistemática e consolidada. Algumas iniciativas remontam a década de 1960, mas, apenas a partir da segunda metade da década de 1990, o sistema nacional passou a se desenvolver, com o Exame Nacional de Cursos ('Provão') e a Avaliação das Condições de Oferta (INSTITUTO NACIONAL DE ESTUDOS E PESQUISAS EDUCACIONAIS ANÍSIO TEIXEIRA, 2000, 2001, 2002b, 2003).

Polêmico desde sua criação, o Provão foi considerado, por muitos, um instrumento, utilizado para a classificação de instituições de nível Superior, mais voltado a uma avaliação punitiva e reguladora, por parte do Estado, levando a ranqueamentos e ameaças de fechamento de instituições sem um bom desempenho, tendo dificuldades para aumentar sua abrangên- 
ENADE 2005 e 21008: desempenho ...

cia, como fazia parte do projeto de avaliação criado pelo MEC (CATANI; OLIVEIRA; DOURADO, 2002). A partir da promulgação da Lei no 10.861 (BRASIL, 2004), que instituiu um Sistema Nacional de Avaliação (Sinaes), passou a ocorrer o Exame Nacional de Desempenho dos Estudantes (Enade), com uma concepção parecida com aquela do Provão, mas com realizações trienais para cada curso abrangido, população amostral e com o mesmo instrumento sendo realizado pelos ingressantes e pelos formandos (BRASIL, 2004). Paralelamente, foi feita tentativa de reforço dos demais parâmetros avaliativos a partir da Comissão Nacional de Avaliação do Ensino Superior (Conaes) (DIAS SOBRINHO, 2010).

Apesar de recente, a estruturação legal dos cursos de Ciências Biológicas, em especial quanto a sua carga horária mínima, foi inserida no Enade em 2005, com novo exame realizado em 2008; e, anteriormente, haviam participado do Exame Nacional de Cursos, de 2000 a 2003, avaliações nacionais introduzidas a partir de 1995, com a Lei no 9.131 (BRASIL, 1995).

Os cursos de Ciências Biológicas sucederam os de História Natural, inicialmente implantados quando da criação da Universidade de São Paulo (USP), em 1934. Após quase cinco décadas, em 3 de setembro de 1979, foi promulgada a Lei $\mathrm{n}^{\circ} 6.648$, que regulamentou a profissão de Biólogo (TOMITA, 1990). Vinte e dois anos depois, a partir de exigência da Lei $n^{\circ}$ 9.394/96 (BRASIL, 1996), foi aprovado o Parecer CNE/CES no 1.301/2001, que estabeleceu as Diretrizes Curriculares Nacionais para os Cursos de Ciências Biológicas, homologado pelo Ministério da Educação, gerando a Resolução CNE/CES n ${ }^{\circ}$, de 11 de março de 2002, e contemplando a formação de professores de biologia (CONSELHO NACIONAL DE EDUCAÇÃO, 2002). Para a integralização dos cursos de Ciências Biológicas, foi estabelecido um tempo mínimo de três anos, e isso, na prática, significou a redução de sua duração em boa parte das Instituições de Ensino Superior (IES) do país, anteriormente de quatro anos. Além disso, foi estabelecida uma carga horária mínima de 2.400 horas, em Parecer do Conselho Nacional de Educação (2007).

Em março de 2009, é publicado o Parecer CNE/CES no 213/2008, de 09/10/2008, regulando os cursos da área da saúde (CONSELHO NACIONAL DE EDUCAÇÃO, 2009), sendo estabelecida uma carga horária mínima de 3.200 horas para os cursos de Ciências Biológicas, com quatro anos de duração quando oferecido em um único período.

Tal exigência passou a ser obrigatória para todas as turmas iniciadas a partir de 2010. Assim, apesar de ter editado em 2008 um Parecer propondo 3.600 horas como carga horária mínima para a formação do biólogo, o Conselho Federal de Biologia (2010) reviu a sua posição e adequou as suas exigências aprovando a Resolução no 213, de março de 2010.

Atualmente, o exercício profissional do biólogo exige carga horária de 2.400 horas, como estabelecia a legislação anterior, e, para formandos a partir de dezembro de 2013, será exigida a carga horária de 3.200 horas.

No presente trabalho, são apresentados resultados obtidos, no Enade 2005 e 2008, para os cursos de Biologia de todas as instituições públicas (estaduais e municipais) do Estado de São Paulo, ligadas ao Conselho Estadual de Educação, que realizaram os dois exames com concluintes, bem como uma universidade e uma instituição isolada, ligadas ao Conselho Nacional de Educação, como controle comparativo.

Também são apresentados os dados referentes à carga horária dos cursos analisados, numa tentativa de correlacionar o desempenho obtido pelos seus egressos, as cargas horárias e as durações dos cursos ministrados pelas instituições analisadas. 


\section{Metodologia}

Os valores referentes ao total de formados e à sua ligação com o sistema público ou privado, ou o tipo de instituição em que o curso foi realizado, foram obtidos diretamente do Censo da Educação Superior dos anos correspondentes, realizado pelo Instituto Nacional de Estudos e Pesquisas Anísio Teixeira (2002a, 2005b, 2008b).

Os dados sobre as participações de todas as escolas no Enade foram obtidos a partir dos relatórios de curso disponíveis para cada instituição que participou do Exame, diretamente no sítio do INEP, assim como outros dados relevantes constantes desses relatórios.

Quando da análise de mais de uma instituição numa dada categoria, os resultados de todas elas foram somados e tratados de forma unificada, exceto quando explicitado.

As duas instituições ligadas ao sistema federal de ensino, uma universidade e uma faculdade isolada, foram sorteadas dentre todas as IES presentes no Estado de São Paulo que oferecem cursos de biologia. O sorteio contemplou uma universidade federal e uma faculdade privada.

Para os valores de médias de desempenho na prova, foram calculados coeficientes de variação, dividindo-se o valor do desvio padrão da amostra, pelo valor da média, e multiplicando o resultado por 100.

Para o Enade 2005, foi relacionado o desempenho das mesmas Instituições em quatro questões objetivas da parte específica, com grau de dificuldade alto e índice de discriminação com classificação de 'muito bom' no próprio relatório geral elaborado pelo Instituto Nacional de Estudos e Pesquisas Anísio Teixeira (2005b), e duas questões discursivas comuns aos formandos dos cursos de bacharelado e de licenciatura.

A duração dos cursos e outras informações referentes a cada instituição foram diretamente obtidas em seus sítios institucionais ou por consulta direta.

\section{Resultados}

A Tabela 1 apresenta os dados referentes à quantidade de formados em cursos de licenciatura em Biologia e em bacharelados em Ciências Biológicas ou Biologia nos últimos anos.

Pelos dados apresentados, percebe-se que os cursos de licenciatura dobraram o número de formados no período ( $106 \%$ de aumento), enquanto os bacharelados tiveram um aumento menor, de $62 \%$, inclusive com leve queda de formados no período entre $2005 \mathrm{e}$ 2008. Em termos da formação em instituições universitárias, nota-se que os aumentos foram menos expressivos nas licenciaturas $(67 \%)$ e nos bacharelados $(43 \%)$.

Outro dado relevante refere-se ao fato de que quase $4 / 5$ da formação de bacharéis $(78 \%)$ ocorria, em 2008, em universidades, enquanto, para as licenciaturas, esse total era de praticamente a metade, o mesmo se dando no total de egressos de cursos superiores do país (dados não apresentados). Do mesmo modo, a formação em instituições públicas, representava praticamente $40 \%$ do total de formados, tanto nas licenciaturas quanto nos bacharelados, enquanto os dados do INEP revelam $23 \%$ para o total de egressos de cursos superiores, correspondendo a cursos realizados em IES públicas (187.758 formados em IES públicas 
ENADE 2005 e $21008:$ desempenho ...

Tabela 1. Quantidade de formados em cursos de Licenciatura ou Bacharelado em Biologia e Ciências Biológicas.

\begin{tabular}{|c|c|c|c|c|c|c|}
\hline \multirow[b]{2}{*}{ Descrição } & \multicolumn{3}{|c|}{ Licenciaturas } & \multicolumn{3}{|c|}{ Bacharelados* } \\
\hline & 2002 & 2005 & 2008 & 2002 & 2005 & 2008 \\
\hline Geral & 4.235 & 6.482 & 8.717 & 6.599 & 10.835 & 10.719 \\
\hline Federais & 455 & 524 & 812 & 1.865 & 2.591 & 2.452 \\
\hline Estaduais & 1.113 & 1.732 & 1.775 & 991 & 1.418 & 1.452 \\
\hline Municipais & 359 & 544 & 738 & 157 & 225 & 273 \\
\hline Particulares & 1.087 & 1.206 & 2.362 & 2.013 & 3.296 & 3.020 \\
\hline Comunitárias & 1.221 & 2.476 & 3.030 & 1.573 & 3.303 & 3.551 \\
\hline Universidades & 2.838 & 3.695 & 4.735 & 5.852 & 8.360 & 8.362 \\
\hline Federais & 455 & 524 & 671 & 1.865 & 2.591 & 2.452 \\
\hline Estaduais & 1.113 & 1.589 & 1.668 & 991 & 1.375 & 1.315 \\
\hline Municipais & 66 & 104 & 96 & 59 & 91 & 0 \\
\hline Particulares & 372 & 47 & 569 & 1.596 & 2.051 & 1.580 \\
\hline Comunitárias & 832 & 1.631 & 1.731 & 1.341 & 2.252 & 2.619 \\
\hline
\end{tabular}

* Inclui bacharelados em Microbiologia, Biologia Marinha, Biologia Molecular, Bioquímica e

Microbiologia, todos com quantidades muito pequenas de formados, à exceção do curso de Biologia.

Fonte: Instituto Nacional de Estudos e Pesquisas Educacionais Anísio Teixeira (2005b).

num total de 800.318) (INSTITUTO NACIONAL DE ESTUDOS E PESQUISAS EDUCACIONAIS ANÍSIO TEIXEIRA, 2008b).

Finalmente, pode-se perceber que os percentuais de egressos de instituições públicas, no total e nas universidades, vêm, sistematicamente, diminuindo, passando de $46 \%$ em 2002, para 39\% em 2008. No mesmo período, a formação em todos os cursos presenciais passou de $32 \%$ para 23\% (INSTITUTO NACIONAL DE ESTUDOS E PESQUISAS EDUCACIONAIS ANÍSIO TEIXEIRA, 2008b).

O Enade de 2005 foi realizado por quase 11 mil concluintes de cursos de biologia no país, de um total de egressos previsto para a população que se cadastrou para a realização do exame cerca de 70\% maior ( 18600), o mesmo ocorrendo em 2008, conforme a Tabela 2.

Os dados revelam algumas características interessantes do exame, nas suas duas edições, destacando-se que, em 2005, a melhor média foi obtida pelo total dos cursos das universidades estaduais paulistas (UE) que realizaram a prova. Nas questões de Formação Geral, à exceção da universidade do sistema federal (UF), as notas foram mais próximas e melhores. $\mathrm{Na}$ parte específica da prova, os valores voltaram a se distanciar, com predomínio de um desempenho melhor em UE. Chamaram a atenção os elevados valores dos Coeficientes de Variação das notas obtidas pela UF, acima de $80 \%$ em todos os casos (Tabela 2).

Em 2008, o comportamento foi um pouco diferente, com diminuição nas notas em EU e aumento de seus Coeficientes de Variação para valores acima de 50\%, parecidos com aqueles da UF, também desta ordem ou até um pouco inferiores. Com isso, os melhores desempenhos nesse ano foram, para a parte específica da prova, da própria UF. Novamente, nas questões que envolveram a formação geral, as notas foram mais semelhantes, à exceção daquelas das UE, nitidamente mais baixas (Tabela 2).

O INEP elabora um Relatório de Curso onde coloca uma série de informações acerca do desempenho dos participantes no exame, comparando-os com os estudantes de institui- 
Cortelazzo, A. L.; Ribeiro, V. K.

Tabela 2. Dados de desempenho no Enade para concluintes de cursos de biologia nas instituições ligadas ao Sistema Estadual de Ensino de SP em comparação com o total do país e com duas instituições de São Paulo ligadas ao Sistema Federal de Ensino.

\begin{tabular}{|c|c|c|c|c|c|c|c|c|}
\hline \multicolumn{2}{|c|}{ Parâmetros } & Brasil & FM & $\mathrm{CM}$ & UM & UE & UF & FF \\
\hline & & \multicolumn{7}{|c|}{ ENADE de 2005} \\
\hline \multicolumn{2}{|l|}{ População* } & 18.634 & 199 & 276 & 102 & 430 & 59 & 71 \\
\hline \multicolumn{2}{|l|}{ Amostra } & 11.790 & 151 & 106 & 71 & 268 & 57 & 30 \\
\hline \multicolumn{2}{|l|}{ Presentes } & 10.933 & 146 & 101 & 68 & 260 & 54 & 23 \\
\hline \multirow[t]{2}{*}{ Total } & Média & 35,5 & 31,0 & 21,4 & 34,7 & 43,0 & 31,7 & 29,8 \\
\hline & $\mathrm{CV}^{* *}$ & 32,1 & 26,1 & 35,7 & 21,9 & 30,9 & 82,6 & 17,8 \\
\hline Formação & Média & 62,0 & 56,4 & 69,1 & 62,2 & 66,8 & 45,3 & 56,8 \\
\hline Geral & CV & 29,0 & 26,2 & 18,7 & 20,1 & 29,4 & 80,1 & 20,8 \\
\hline Formação & Média & 26,6 & 22,6 & 24,7 & 25,6 & 35,1 & 27,2 & 20,8 \\
\hline \multirow[t]{2}{*}{ Específica } & $\mathrm{CV}$ & 42,5 & 36,7 & 32,7 & 31,3 & 37,0 & 86,8 & 29,8 \\
\hline & & \multicolumn{7}{|c|}{ ENADE de 2008} \\
\hline \multicolumn{2}{|l|}{ População } & 25.872 & 249 & 262 & 85 & 512 & 73 & 42 \\
\hline \multicolumn{2}{|l|}{ Amostra } & 16.699 & 189 & 152 & 70 & 364 & 63 & 34 \\
\hline \multicolumn{2}{|l|}{ Presentes } & 15.005 & 184 & 139 & 67 & 339 & 62 & 29 \\
\hline \multirow[t]{2}{*}{ Total } & Média & 39,1 & 33,4 & 42,8 & 44,1 & 36,7 & 51,1 & 34,9 \\
\hline & $\mathrm{CV}$ & 36,1 & 27,8 & 28,5 & 24,7 & 53,5 & 49,3 & 26,6 \\
\hline Formação & Média & 50,2 & 46,3 & 54,9 & 53,8 & 38,2 & 46,8 & 47,8 \\
\hline Geral & $\mathrm{CV}$ & 34,5 & 34,4 & 29,3 & 22,3 & 57,8 & 51,7 & 30,3 \\
\hline Formação & Média & 35,5 & 29,1 & 38,7 & 40,9 & 36,2 & 52,5 & 30,6 \\
\hline Específica & CV & 42,8 & 33,3 & 35,1 & 31,5 & 56,0 & 50,5 & 31,7 \\
\hline
\end{tabular}

FM - Faculdades municipais; CM - Centros universitários municipais; UM - Universidades municipais; UE - Universidades estaduais; UF -Universidade ligada ao sistema federal; FF - Faculdade ligada ao sistema federal; " População de egressos das escolas do sistema federal de ensino e das que aderiram ao Enade no caso das IES ligadas ao sistema estadual de ensino; ${ }^{* *}$ Coeficiente de variação (\% do desvio padrão sobre a média obtida).

Fonte: Elaborado pelos autores.

ções que têm a mesma natureza jurídica (estadual, municipal, federal ou privada) e a mesma categoria administrativa (faculdade, centro universitário, universidade). Além disso, os resultados da instituição são colocados frente àqueles obtidos no Estado da Federação pelo conjunto de suas IES, bem como o total geral do desempenho de todas as IES do país.

Além disso, o INEP edita um relatório para cada curso, analisando a prova de uma forma geral, o desempenho dos cursos, a performance dos estudantes, seu perfil socioeconômico etc. ${ }^{3}$

O Enade 2005 para os cursos de biologia foi formado de duas partes: a primeira, de natureza geral, apresentou sete questões objetivas de múltipla escolha (peso de 55\%) e 3 discursivas (peso 45\%); teve por objetivo investigar a aquisição de competências, habilidades e conhecimentos de formação geral considerados essenciais na formação de um estudante de qualquer área da Educação Superior. A segunda, relativa ao componente específico da área de

\footnotetext{
${ }^{3}$ Disponível em: <http://www.inep.gov.br/download/enade/2005/relatorios/Biologia.pdf>. Acesso em: 20 abr. 2010. 
ENADE 2005 e 21008: desempenho ...

biologia, foi composta de 25 questões de múltipla escolha do componente específico (peso $75 \%$ ) e 6 questões discursivas (peso 25\%), envolvendo situações-problema do núcleo comum, dos cursos de bacharelado e de licenciatura. Como nos demais Exames, a parte específica contribui com $75 \%$ do total da nota final.

Em 2005, dos 422 cursos avaliados, 192 (46\%) obtiveram conceito 3, 19 cursos obtiveram $5(4,5 \%)$ e 1 curso obteve nota 1 (0,2\%). Dos 422 participantes, 265 (63\%) eram oriundos de instituições privadas, $84(20 \%), 58(14 \%)$ federais e os $15(3 \%)$ restantes, municipais. $\mathrm{Na}$ região sudeste, os melhores conceitos ficaram com as instituições estaduais e federais, que totalizaram $67 \%$ de todos os conceitos 4 do país e $81 \%$ dos conceitos 5 . Em termos de sua organização acadêmica, 59\% dos cursos avaliados provinham de universidades, seguidas das faculdades e institutos superiores de educação, com 19\%.

Em função dos resultados apresentados no Relatório para o Curso de biologia em 2005, foram escolhidas duas questões discursivas e quatro questões objetivas do componente específico da prova, mais discriminador do que os conteúdos da formação geral. As duas questões discursivas da parte específica da prova, de números 4 e 5 , foram as questões respondidas por todos os estudantes, independentemente de formandos de cursos de bacharelado ou de licenciatura.

As questões objetivas foram escolhidas dentre as respondidas por todos os estudantes e que tiveram um elevado índice de discriminação da parte específica da prova (questões 15 e 20) segundo escolha a partir do relatório do Instituto Nacional de Estudos e Pesquisas Anísio Teixeira (2005b), e as de número 27 e 29, respondidas diferentemente por formandos de bacharelado ou de licenciatura.

Os resultados do desempenho confirmam uma melhor performance por parte dos estudantes de cursos de universidades estaduais, seguidos pelo dos alunos da universidade federal analisada. A média de desempenho na parte discursiva chegou a ser maior em mais de sete vezes que a obtida pelas faculdades municipais e mais de 14 vezes da obtida pela faculdade ligada ao sistema federal para a questão de número 4, e de 4, e dez vezes para a questão número 5 (Tabela 3).

A parte objetiva da prova específica revelou diferenças menores entre as IES analisadas. Entretanto, prevaleceu o melhor desempenho dos egressos dos cursos ministrados em universidade estadual, seguido da instituição universitária federal ou municipal. Exceção ao desempenho foi observada na questão 29, na qual o desempenho na IES universitária federal foi superior (Tabela 3). Tais dados revelam, ainda, que o desempenho médio dos egressos de cursos situados no Estado de São Paulo não é superior àquele observado pela média dos egressos do país como um todo.

Do mesmo modo, fica evidente que a organização acadêmica com melhor desempenho, em todas as situações, é a estrutura universitária. Com relação à organização como centro universitário, aparentemente, não é um fator determinante para um desempenho superior às instituições isoladas de ensino. Finalmente, quanto à natureza jurídica, o conjunto das IES federais prevalece com uma maior frequência que as estaduais, o que, no caso específico de São Paulo, se inverte, conforme revelam os dados apresentados na Tabela 3. 
Cortelazzo, A. L.; Ribeiro, V. K.

Tabela 3. Desempenho dos estudantes dos cursos de biologia das escolas isoladas municipais (FM), centros universitários municipais (CM), universidades municipais (UM), estaduais (UE), comparados aos de uma instituição universitária (UF) e uma instituição isolada (FF) do sistema federal de ensino e situada em São Paulo.

\begin{tabular}{|c|c|c|c|c|c|c|}
\hline & FM & CM & UM & UE & UF & FF \\
\hline Questão 4 & & & & & $\mathrm{SP}^{*}=6,6$ & $\mathrm{BR}^{* *}=6,2$ \\
\hline Escola ${ }^{* * *}$ & 2,2 & 4,0 & 4,4 & 15,8 & 12,5 & 1,1 \\
\hline Cat. Adm. ${ }^{* * * *}$ & 3,0 & 3,0 & 3,0 & 13,2 & 12,3 & 3,3 \\
\hline Org. Acad..$^{* * * * *}$ & 2,8 & 3,0 & 7,7 & 7,7 & 7,7 & 2,8 \\
\hline Questão 5 & & & & & $S P=10,8$ & $B R=9,4$ \\
\hline Escola & 4,7 & 9,8 & 7,7 & 19,9 & 20,1 & 2,0 \\
\hline Cat. Adm. & 6,3 & 6,3 & 6,3 & 10,7 & 14,9 & 7,4 \\
\hline Org. Acad. & 6,2 & 7,8 & 10,5 & 10,5 & 10,5 & 6,2 \\
\hline Questão 15 & & & & & $\mathrm{SP}=39,4$ & $\mathrm{BR}=39,8$ \\
\hline Escola & 30,1 & 36,5 & 36,5 & 51,2 & 35,2 & 39,1 \\
\hline Cat. Adm. & 34,7 & 34,7 & 34,7 & 41,2 & 42,6 & 38,5 \\
\hline Org. Acad. & 38,9 & 38,2 & 40,6 & 40,6 & 40,6 & 38,9 \\
\hline Questão 20 & & & & & $\mathrm{SP}=39,3$ & $B R=38,0$ \\
\hline Escola & 24,9 & 38,4 & 32,4 & 66,1 & 50 & 30,4 \\
\hline Cat. Adm. & 29,8 & 29,8 & 29,8 & 40,1 & 52,8 & 31,8 \\
\hline Org. Acad. & 27,3 & 31,6 & 41,7 & 41,7 & 41,7 & 27,3 \\
\hline Questão 27 & & & & & $\mathrm{SP}=38,5$ & $B R=38,1$ \\
\hline Escola & 38,0 & 31,6 & 41,0 & 52,1 & 37,0 & 21,7 \\
\hline Cat. Adm. & 38,3 & 38,3 & 38,3 & 39,6 & 44,5 & 34,9 \\
\hline Org. Acad. & 33,7 & 33,7 & 40,1 & 40,1 & 40,1 & 33,7 \\
\hline Questão 29 & & & & & $S P=26,5$ & $B R=25,1$ \\
\hline Escola & 24,3 & 22,4 & 28,7 & 32,6 & 40,7 & 30,4 \\
\hline Cat. Adm. & 25,9 & 25,9 & 25,9 & 21,3 & 30,5 & 23,9 \\
\hline Org. Acad. & 21,8 & 23,4 & 26,3 & 26,3 & 26,3 & 21,8 \\
\hline
\end{tabular}

"Desempenho no Estado de São Paulo para a questão; " Desempenho nacional para a questão; * *** Instituição analisada; **** Cat. Adm.: IES municipal, estadual, federal ou privada; ${ }^{* * * *}$ Org. Acad.: organização acadêmica como IES isolada, centro universitário ou universidade.

Fonte: Elaborado pelos autores.

Pela Tabela 4, percebe-se que os cursos de biologia ministrados pelas IES pesquisadas apresentam carga horária que oscila entre duas mil e oitocentas e quatro mil, duzentas e vinte horas de atividades, o que representa uma variação de $50 \%$ da carga horária total. Destaque-se o fato de que não há uma relação absoluta entre a carga horária e a natureza administrativa ou a organização acadêmica das instituições. Entretanto, os menores valores, de forma geral, se deram nos cursos ministrados pelas faculdades isoladas municipais e, os maiores, nos centros universitários municipais.

Para fins de comparação, foram selecionadas as duas instituições de cada categoria (faculdade, centro universitário ou universidade), com os extremos de carga horária, a fim de verificar o desempenho de seus estudantes no Exame de 2005 e de 2008. Os resultados encontram-se descritos na Tabela 5. Os dados revelam que a carga horária do curso não interfere no desempenho de seus estudantes, em nenhuma das categorias analisadas.

Para o Enade de 2005, percebe-se que a faculdade isolada de menor carga horária $(2.800 \mathrm{~h})$ em relação à de maior carga horária total $(3.720 \mathrm{~h})$, a despeito da diferença entre os cursos ministrados (carga horária 33\% maior), teve praticamente o mesmo desempenho, com coeficientes de variação equiparáveis nos dois grupos. Com os centros universitários analisa- 
ENADE 2005 e 21008: desempenho ...

Tabela 4. Duração dos cursos de biologia nas IES que realizaram o ENADE 2005 e 2008, em horas de atividades e prazos de integralização mínimo e máximo.

\begin{tabular}{|c|c|c|c|c|c|}
\hline \multirow[b]{2}{*}{ IES $^{*}$} & \multicolumn{5}{|c|}{ Dados gerais } \\
\hline & Tipo & Período & Intervalo de duração** & Mínimo & Máximo \\
\hline \multirow[t]{2}{*}{ FM } & Bacharelado & Noturno & $3.200 \mathrm{~h}$ & 8 sem. & 12 sem. \\
\hline & Licenciatura & Noturno & $2.800 \mathrm{~h}$ a $3.720 \mathrm{~h}$ & 6 sem & 10 sem. \\
\hline \multirow[t]{2}{*}{$\mathrm{CM}$} & Bacharelado & Integr./Not. & 3.944h a $4.220 \mathrm{~h}$ & 8 sem. & 12 sem. \\
\hline & Licenciatura & Integr./Not. & $3.264 \mathrm{~h}$ a $4.220 \mathrm{~h}$ & 8 sem. & 12 sem. \\
\hline \multirow[t]{2}{*}{ UM } & Bacharelado & Matutino & $3.490 h$ & 8 sem. & 14 sem. \\
\hline & Licenciatura & Noturno & $3.558 \mathrm{~h}$ & 8 sem. & 14 sem. \\
\hline \multirow[t]{4}{*}{ UE } & Bacharelado & Integral & 3.210h a 4.050h & 8 sem. & 14 sem. \\
\hline & Bacharelado & Noturno & 3.210h a $3.330 \mathrm{~h}$ & 10 sem. & 18 sem. \\
\hline & Licenciatura & Integral & 3.270h a $3.930 h$ & 8 sem. & 12 sem. \\
\hline & Licenciatura & Noturno & $3.270 \mathrm{~h}$ a $3.930 \mathrm{~h}$ & 10 sem. & 15 sem. \\
\hline \multirow[t]{2}{*}{ UF } & Bacharelado & Integral & $3.540 \mathrm{~h}$ & 8 sem. & $\mathrm{NI}^{\star \star \star}$ \\
\hline & Licenciatura & Vesp./Not. & $3.720 \mathrm{~h}$ & 8 sem. & \\
\hline FF & Bacharelado & Noturno & $\mathrm{NI}$ & $\mathrm{NI}$ & $\mathrm{NI}$ \\
\hline
\end{tabular}

"FM: Faculdades municipais; CM: Centros Universitários municipais; UM: Universidades municipais; UE: Universidades estaduais; UF: Universidade do sistema federal de ensino; FF: Faculdade do sistema federal de ensino; ** Intervalo de duração quando foi analisado mais de um curso, com carga horária diferente; "*N"NI: dado não informado pela IES.

Fonte: Elaborado pelos autores.

Tabela 5. Dados de desempenho no Enade para concluintes de cursos de biologia nas instituições de menor (m) e de maior (M) carga horária, segundo sua organização administrativa como Faculdade Municipal (FM), Centro Universitário Municipal (CM), Universidade Municipal (UM) ou Estadual (UE).

\begin{tabular}{|c|c|c|c|c|c|c|c|c|}
\hline \multicolumn{2}{|c|}{ Parâmetros } & FMm & FMM & $\mathrm{CMm}$ & CMM & UEm & UEM & UMM \\
\hline & & \multicolumn{7}{|c|}{ ENADE 2005} \\
\hline \multirow[t]{2}{*}{ Total } & Média & 32,5 & 32,8 & 36,6 & 34,7 & 40,8 & 40,4 & 34,7 \\
\hline & $\mathrm{CV}^{*}$ & 20,9 & 29,9 & 21,9 & 20,5 & 27,5 & 41,5 & 21,9 \\
\hline Formação & Média & 60,8 & 59,6 & 71,2 & 66,1 & 65,9 & 61,0 & 62,2 \\
\hline Geral & CV & 17,4 & 27,2 & 18,0 & 19,8 & 32,5 & 40,2 & 20,1 \\
\hline Formação & Média & 23,1 & 23,9 & 25,6 & 25,1 & 32,4 & 33,5 & 25,6 \\
\hline \multirow[t]{2}{*}{ Específica } & $\mathrm{CV}$ & 33,8 & 41,8 & 31,3 & 34,7 & 30,6 & 47,5 & 31,3 \\
\hline & & \multicolumn{7}{|c|}{ ENADE 2008} \\
\hline \multirow[t]{2}{*}{ Total } & Média & 35,7 & 36,5 & 44,1 & 43,5 & 59,8 & 27,4 & 44,1 \\
\hline & CV & 29,7 & 28,5 & 24,7 & 30,1 & 15,7 & 95,6 & 24,7 \\
\hline Formação & Média & 53,1 & 52,7 & 53,8 & 56,7 & 58,2 & 29,2 & 53,8 \\
\hline Geral & CV & 30,3 & 33,0 & 22,3 & 30,3 & 27,3 & 100,0 & 22,3 \\
\hline Formação & Média & 30,0 & 31,1 & 40,9 & 40,9 & 60,4 & 26,8 & 40,9 \\
\hline Específica & $\mathrm{CV}$ & 33,7 & 32,8 & 31,5 & 36,8 & 16,4 & 97,8 & 31,5 \\
\hline
\end{tabular}

* Coeficiente de variação expresso em porcentagem do desvio padrão em relação à média obtida.

Fonte: Elaborado pelos autores. 
dos ocorreu o mesmo: valores de desempenho similares e com coeficientes de variação equivalentes, a despeito do maior curso $(4.220 \mathrm{~h})$ ter duração $29 \%$ maior que o de menor carga horária (3.264h). Finalmente, para os egressos de cursos de universidades estaduais, a situação não foi diferente: médias até ligeiramente superiores para o curso de menor duração (3.210h) em relação ao de maior (4.050h). Para reforçar os dados de desempenho, foram ainda compilados os valores de egressos de universidade municipal, corroborando as afirmações de que o desempenho dos egressos não está relacionado com a duração do curso (Tabela 5).

No exame realizado em 2008, o mesmo foi observado, com desempenhos semelhantes nas faculdades isoladas e centros universitários. Entretanto, os dados relativos aos egressos de universidades revelaram um altíssimo coeficiente de variação da IES universitária de maior carga horária, chegando a 100\% do valor da média, com resultados numericamente inferiores aos dos cursos universitários de menor carga horária, denominados UEm e UM (Tabela 5).

O Sistema CFBio/CRBios (Conselho Federal de Biologia e seus Conselhos Regionais), pela Resolução n 300, de 07 de dezembro de 2012 (CONSELHO FEDERAL DE BIOLOGIA, 2012), aprovou a proposta de uma carga horária mínima e tempo de integralização para o Curso de Bacharelado em Ciências Biológicas (presencial), adequando as 3.600 horas inicialmente previstas em 2008 para três mil e duzentas horas horas, em virtude da Resolução no 4, de 2009, do Conselho Nacional de Educação (2009).

O núcleo de formação básica, segundo o CFBio, deve ser formado por 1.995 horas, contemplando os conteúdos de: 1) Biologia Celular, Molecular e Evolução (765h), com conteúdos de Biologia Celular, Histologia, Embriologia, Anatomia, Microbiologia, Imunologia, Parasitologia, Bioquímica, Biofísica, Biologia Molecular, Fisiologia, Genética e Evolução; 2) Diversidade Biológica (690h), com conteúdos de Zoologia, Botânica e Micro-organismos; 3) Ecologia (240h), com Ecologia, Conservação e Manejo, Biogeografia e Gestão Ambiental; 4) Fundamentos das Ciências Exatas e da Terra (240h), com Geologia, Paleontologia, Matemática e Bioestatística, Física e Química; e 5) Fundamentos Filosóficos e Sociais (60h), com Bioética, Filosofia, Sociologia e Antropologia, além da Legislação profissional do Biólogo.

Além da formação básica, o CFBio recomenda 1.205h de conteúdos específicos, destinados à elaboração de trabalho de conclusão de curso (60h), atividades complementares (50h), estágio (360h), componentes curriculares obrigatórios (510h) e eletivos (225h).

As IES analisadas, com exceção de três faculdades isoladas, já apresentam, pelo menos, três mil e duzentas horas de duração em seus cursos desde 2005. A análise das estruturas curriculares disponíveis revela, entretanto, que boa parte das IES deverá rever suas matrizes curriculares para os ingressantes a partir de 2010, se desejarem se adequar à formação recomendada pelo CFBio, a fim de apresentarem as 1.995 horas de atividades curriculares ligadas à formação geral. Tal adequação não tem efeito para a autorização do funcionamento de cursos, reconhecimento ou renovações de reconhecimento estabelecidos pelos sistemas de ensino, mas poderá levar a uma diferenciação nas atribuições para o exercício profissional do biólogo no país. 
ENADE 2005 e 21008: desempenho ...

\section{Discussão}

Os cursos de Ciências Biológicas existentes no país guardam características diferenciadas da média nacional para o conjunto de cursos de graduação: praticamente $2 / 5$ (40\%) dos cursos são desenvolvidos em instituições públicas, o que representa o dobro da média nacional para a graduação. Além disso, 4/5 dos bacharelados são desenvolvidos em universidades, dado muito superior ao dos demais cursos, que atingem cerca de metade dos formados. Tais características possivelmente se relacionam ao fato de os cursos requererem grande quantidade de atividades práticas de laboratório, equipamentos mais sofisticados, o que leva às estruturas universitárias instaladas, com maior quantidade de laboratórios que podem servir a vários cursos e, no total, acabarem por apresentar melhores condições de oferta.

A estruturação dos cursos tem se revelado adequada ao que prevê a legislação. A introdução de um sistema de renovações de reconhecimento a partir da LDB contribuiu para isso: os cursos devem se adequar às determinações constantes nas Diretrizes Curriculares Nacionais e à duração prevista, pois passam a receber, periodicamente, especialistas que analisam se tais determinações estão sendo respeitadas. Assim, a despeito de ainda restar muito a ser feito, ao menos em termos de projeto pedagógico, os cursos têm se mostrado adequados aos mínimos estabelecidos. Desse modo, quando a carga horária dos cursos passa das 2.400 horas inicialmente propostas para as três mil e duzentas previstas na Resolução CNE n 4/2009 (CONSELHO NACIONAL DE EDUCAÇÃO, 2009), e dá prazo para isso ser iniciado, as IES passam a reestruturar suas matrizes curriculares visando o cumprimento da nova determinação.

É sabido que, nos resultados das avaliações do Enade, as instituições públicas federais e estaduais têm tido, no geral, melhor desempenho de seus estudantes egressos. Esse comportamento foi verificado também para os cursos de biologia ministrados no Estado de São Paulo, onde prevaleceu a nota dessas instituições, a despeito de algumas não terem participado do Exame, o que é lamentável, pois distorce os resultados do conjunto dos cursos do Estado. Para a consolidação de um Sistema Nacional de avaliação, ainda que haja reservas quanto aos instrumentos utilizados, é necessária a participação de todas as IES do país que, assim, poderá permitir uma análise do todo, e não apenas de parte dele, ainda que a maioria dos cursos se faça presente nos Exames nacionais.

O Enade trouxe duas novidades com relação aos procedimentos anteriormente adotados no Exame Nacional de Cursos (Provão): a primeira foi a realização do mesmo exame pelos ingressantes e pelos formandos da IES, e não apenas por estes últimos, como antes. A segunda foi a realização de exame com periodicidade trienal e amostral. Porém, há críticas a estes dois fatores.

A primeira refere-se ao fato de que o exame deixa de exigir um mínimo conceitual e passa a ser comparativo com relação aos ingressantes. Se, de um lado, o peso do conceito da instituição é pouco influenciado pelo desempenho dos ingressantes, não deixa de ser complicado acreditar que esta possa ter melhor desempenho se seus egressos mostrarem performance mais distanciada de seus ingressantes, ainda que não haja um resultado minimamente satisfatório quanto aos conhecimentos e habilidades adquiridos. Em contrapartida, essa característica pode significar um tipo de prova mais dinâmico, voltado em tese à evolução do desempe- 
nho do aluno ao longo de sua formação (BRITO, 2008), em contrapartida ao modelo estático representado pelo Provão, mesmo considerando que, no geral, os ingressantes que realizam um exame não serão os mesmos que o farão como concluintes.

A segunda grande crítica, parcialmente resolvida, era decorrente de a prova ser feita a partir de uma amostra, e não da população total avaliada, e, ainda, que a maior parte dos cursos tenha duração de quatro anos, os ingressantes que fazem a prova não necessariamente terão a oportunidade de realizá-la novamente, dada sua periodicidade trienal.

No que diz respeito ao empenho dos estudantes na realização das provas, isso começa a ser questionado: os coeficientes de variação são excessivamente altos para a universidade do sistema federal e, em 2008, também para o conjunto das universidades estaduais, o que pode significar estar ocorrendo um boicote às respostas do Exame.

Segundo Leitão et al. (2010), o boicote ao Enade é reduzido, não tendo ultrapassado $3,5 \%$ da população avaliada em nenhuma das edições do exame. Os autores salientam: que alguns cursos são mais afetados pelo boicote (e não relacionam biologia como um deles), que as IES públicas são mais afetadas que as privadas, e que os 'boicotantes' são alunos descontentes com aspectos físicos e curriculares da instituição, renda familiar maior, pais mais escolarizados e egressos de Ensino Médio em escola privada (LEITÃO et al., 2010).

A avaliação do desempenho acadêmico em nível nacional e enquanto política pública de avaliação do Ensino Superior é atividade de extrema complexidade. Além dos aspectos levantados anteriormente, fica claro que o sucesso da iniciativa depende de todos os atores envolvidos, em especial, os estudantes. Segundo Paiva (2008), o princípio da obrigatoriedade é o único que pode garantir o sucesso dessa avaliação e, se houver equidade, aumentará a possibilidade de participação dos estudantes, embora não se possam assegurar os resultados. De certa forma, a partir do momento que o Enade passa a ser considerado um 'componente curricular' do curso, sua obrigatoriedade fica tão evidente quanto era a do Provão, que fazia constar, no diploma, a participação do estudante. Além disso, como até 2008 o exame foi amostral, a equidade não ficava garantida: se, de um lado, o exame é tratado como um componente curricular obrigatório no Sistema Federal, nem todos os estudantes eram obrigados a cumpri-lo, o que facilita o descontentamento e, a partir daí, o boicote.

Segundo Verhine, Dantas e Soares (2006), há muitas similaridades entre o Enade e o extinto Provão, especialmente no que diz respeito à elaboração e à administração dos instrumentos. Os autores salientam que as principais diferenças referem-se à introdução de um componente de Formação Geral no Enade, comum a todos os campos do conhecimento, além do envolvimento de alunos ingressantes. A esse respeito, fica claro que o componente relativo à Formação Geral é aquele em que ocorre um melhor desempenho das instituições, independentemente de sua natureza jurídica ou organização acadêmica. Tais resultados estão coerentes com a proposta desta parte do exame, mais próxima de exames vestibulares que ocorrem nas grandes instituições, em especial no Estado de São Paulo.

A checagem de uma formação geral acaba aproximando o grupo dos alunos ingressantes do dos formandos, e merece um estudo mais detalhado sobre os seus reais efeitos no Exame Nacional. Nesse contexto, não seria esta uma característica trazida do Ensino Médio, cujo objetivo é formar o cidadão e, desse modo, mais pertinente a uma abordagem no Exame Nacional do Ensino Médio (ENEM)? A esse respeito, ficaria mais clara a evolução dos estudantes, visto que o ENEM foi criado para que o egresso do Ensino Médio tivesse um referen- 
ENADE 2005 e 21008: desempenho ...

cial de suas competências e habilidades frente ao conjunto de egressos do Ensino Médio (CORTELAZZO, 2003). Isso seria mais real que aplicar-se um instrumento que, em sua parte específica, deveria levar os ingressantes a um péssimo resultado, de conformidade com o curso avaliado. Em outros termos, um bom desempenho dos ingressantes pode significar uma inadequação da parte específica da prova para a medição da influência do ensino no desempenho do estudante, criando uma prova excessivamente fácil e, com isso, pouco significativa para a análise do desempenho dos egressos. Portanto, a redução do exame para conteúdos mínimos ficaria aquém do patamar necessário para uma efetiva análise de desempenho dos formados nos cursos analisados. o egresso do ensino médio dos Exames Nacionais.

Finalmente, deve-se registrar que os resultados revelaram que as cargas horárias dos cursos não interferiram no desempenho dos estudantes, independentemente da natureza jurídica ou organização administrativa da IES analisada. Isso não significa não ser importante a duração do curso, pelo contrário, desempenhos satisfatórios só podem ser alcançados a partir de certa carga horária do curso. Também se deve levar em conta que a proposta do Exame não é a de discriminar ou classificar, mas checar habilidades e conceitos mínimos adquiridos ao longo da graduação. Infelizmente, a riqueza com que os resultados poderiam contribuir para uma reflexão a respeito do desenvolvimento dos conteúdos de um dado curso, sua inserção local, sua vocação e características peculiares, acaba dando lugar a ranqueamentos inevitáveis, aliás, à semelhança do dos 'provões', deturpando a finalidade do Exame e, mais que isso, atribuindo-lhe características avaliativas que distorcem seus objetivos.

Cumpre salientar que o Parecer CNE/CES no 213/2008, de 09 de outubro de 2008 e homologado em 11 de março de 2009 (BRASIL, 2009), esclarece ser competência do Conselho Nacional de Educação deliberar sobre Diretrizes Curriculares Nacionais, assim como sobre a duração, tempo de integralização e carga horária dos cursos: "[...] Os Conselhos Profissionais fiscalizam e acompanham o exercício profissional que se inicia após a formação acadêmica, não lhes cabendo qualquer ingerência sobre os cursos regulados pelo sistema de ensino do País [...]” (BRASIL, 2008, p. 22).

Finalmente, deve ser considerado que as imperfeições salientadas e as características apresentadas no presente trabalho fazem parte integrante do processo de construção da avaliação do Ensino Superior no Brasil. Avançou-se muito a partir da década de 1990 e ainda há muito a avançar, em especial, no processo como um todo, que deve contemplar avaliações de desempenho, mas não ficar restrito apenas a elas.

\section{Conclusão}

Os cursos de biologia apresentam características peculiares em relação ao conjunto de cursos de graduação oferecidos no país: são preferencialmente oferecidos em instituições universitárias, especialmente os bacharelados, e há uma participação maior das instituições públicas nessa formação, quando comparada aos outros cursos.

O desempenho dos alunos formandos em cursos ligados a universidades estaduais foi maior no Enade 2005, mas diminuiu em 2008, quando as universidades ligadas ao sistema federal tiveram melhor desempenho. O desempenho diferenciado fica mais evidente quando se levam em conta as questões de alto índice de discriminação. 
Os coeficientes de variação das médias do desempenho das Universidades estaduais aumentaram significativamente de 2005 para 2008.

O desempenho no Enade 2005 ou de 2008 não teve relação com a carga horária total dos cursos. Para uma mesma organização acadêmica, as IES com menor carga horária tiveram desempenho semelhante, ou até maior, do que aquelas com carga horária maior.

\section{Referências}

BRASIL. Despachos do Ministro. Em 10 de março de 2009. Diário Oficial da União, Brasília, 11 mar. 2009. Seção 1, p. 11. Disponível em: <http://www.jusbrasil.com/diarios/ 534558/pg-11-secao-1-diario-oficial-da-uniao-dou-de-11-03-2009>. Acesso em: 17 abr. 2013.

Despachos do Ministro. Em 20 de maio de 2008. Diário Oficial da União, Brasília, 21 maio 2008. Seção 1, p. 22. Disponível em: <http://www.jusbrasil.com.br/ diarios/588772/dou-secao-1-21-05-2008-pg-22>. Acesso em: 15 abr. 2013.

Lei $n^{\circ}$ 9.131, de 24 de novembro de 1995. Diário Oficial da União, Brasília, 24 nov. 1995. p. 19.257. (Edição extra). Disponível em: <http://www.planalto.gov.br/ ccivil_03/Leis/L9131.htm>. Acesso em: 3 out. 2010.

. Lei $\mathbf{n}^{\circ} \mathbf{9 . 3 9 4}$, de 20 de dezembro de 1996. Estabelece as diretrizes e bases da educação nacional. Brasília: Presidência da República, 1996. Disponível em: <http://www.planalto.gov.br/ccivil_03/Leis/L9394.htm>. Acesso em: 12 abr. 2013.

. Lei $n^{\circ}$ 10.861, de 14 de abril de 2004. Institui o Sistema Nacional de Avaliação da Educação Superior - SINAES e dá outras providências. Diário Oficial da União, Brasília, 15 abr. 2004. Seção 1, p. 3. Disponível em: <http://www.planalto.gov.br/ccivil_03/ _ato2004-2006/2004/lei/110.861.htm>. Acesso em: 03 out. 2010.

BRITO, M. R. F. O Sinaes e o Enade: da concepção à implantação. Avaliação, Campinas, v. 13, n. 3, p. 841-850, 2008.

CATANI, A. M.; OLIVEIRA, J. F.; DOURADO, L. F. A política de avaliação da educação superior no Brasil em questão. In: DIAS SOBRINHO, J.; RISTOFF, D. I. (Org.).

Avaliação democrática. Florianópolis: Insular, 2002. p. 99-118.

CONSELHO FEDERAL DE BIOLOGIA. Resolução nº 300, de 07 de dezembro de 2012. Estabelece os requisitos mínimos para o biólogo atuar em pesquisa, projetos, análises, perícias, fiscalização, emissão de laudos, pareceres e outras atividades profissionais nas áreas de meio ambiente e biodiversidade, saúde e, biotecnologia e produção. Diário Oficial da União, Brasília, 27 dez. 2012. Seção 1. Disponível em: <http:/ / www.cfbio.gov.br/ resolucoes-cfbio/144-resolucao-no-300-de-7-de-dezembro-de-2012>. Acesso em: 15 abr. 2013. 
ENADE 2005 e 21008: desempenho ...

CONSELHO FEDERAL DE BIOLOGIA. Resolução no 213, de 20 de março de 2010. Estabelece os requisitos mínimos para o Biólogo atuar em pesquisa, projetos, análises, perícias, fiscalização, emissão de laudos, pareceres e outros serviços nas áreas de meio ambiente, saúde e biotecnologia. Diário Oficial da União, Brasília, 24 mar. 2010. Seção 1, p. 100. Disponível em: <http://www.jusbrasil.com.br/diarios/1588734/dou-secao-1-24-032010-pg-100 >. Acesso em: 15 abr. 2013.

CONSELHO NACIONAL DE EDUCAÇÃO. Parecer CNE/CES 08/2007. Dispõe sobre carga horária mínima e procedimentos relativos à integralização e duração dos cursos de graduação, bacharelados, na modalidade presencial. Diário Oficial da União, Brasília, 13 set. 2007. Disponível em: <http://portal.mec.gov.br/cne/arquivos/pdf/2007/ pces008_07.pdf >. Acesso em: 15 out. 2010.

Resolução CNE/CES 4, de 06 de abril de 2009. Dispõe sobre carga horária mínima e procedimentos relativos à integralização e duração dos cursos de graduação em Biomedicina, Ciências Biológicas, Educação Física, Enfermagem, Farmácia, Fisioterapia, Fonoaudiologia, Nutrição e Terapia Ocupacional, bacharelados, na modalidade presencial. Diário Oficial da União, Brasília, 07 abr. 2009. Seção 1, p. 27. Disponível em: <http://portal.mec.gov.br/dmdocuments/rces004_09.pdf>. Acesso em: 15 out. 2010.

. Resolução CNE/CES 7, de 11 de março de 2002. Estabelece as Diretrizes Curriculares para os cursos de Ciências Biológicas. Diário Oficial da União, Brasília, 26 mar. 2002. Seção 1, p. 3. Disponível em: <http://portal.mec.gov.br/cne/arquivos/pdf/ rces07_02.pdf>. Acesso em: 15 out. 2010.

COORDENADORIA DE APERFEIÇOAMENTO DE PESSOAL DO ENSINO SUPERIOR. Avaliação da pós-graduação. Brasília: Capes, [2010?]. Disponível em: $<$ http:/ /www.capes.gov.br/avaliacao/avaliacao-da-pos-graduacao>. Acesso em: 20 set. 2010.

CORTELAZZO, A. L. Utilização do ENEM pelas universidades estaduais paulistas: abordagem quantitativa da abrangência do exame e desempenho dos egressos de escolas públicas e privadas de ensino médio. Ensaio: avaliação e políticas públicas em educação, Rio de Janeiro, v.11, n. 39, p. 210-221, 2003.

DIAS SOBRINHO, J. Avaliação e transformações da educação superior brasileira (1995-2009): do Provão ao Sinaes. Avaliação, Campinas, v. 15, n. 1, p. 195-224, 2010.

DIAS SOBRINHO, J.; RISTOFF, D. I. Universidade desconstruída. Florianópolis: Insular, 2003.

GATTI, B. A. Avaliação institucional e acompanhamento de Instituições de Ensino Superior. Estudos em Avaliação Educacional, São Paulo, n. 21, p. 93-108, 2000.

INSTITUTO NACIONAL DE ESTUDOS E PESQUISAS EDUCACIONAIS ANÍSIO TEIXEIRA. Exame nacional de cursos: relatório síntese. Brasília, 2000.

Exame nacional de cursos: relatório síntese. Brasilia, 2001. 
Cortelazzo, A. L.; Ribeiro, V. K.

INSTITUTO NACIONAL DE ESTUDOS E PESQUISAS EDUCACIONAIS ANÍSIO TEIXEIRA. Censo da educação superior: sinopse. Brasília, 2002a. Disponível em: <http://portal.inep.gov.br/web/censo-da-educacao-superior>. Acesso em: 20 abr. 2010.

Exame nacional de cursos: relatório síntese. Brasília, 2002b.

Exame nacional de cursos: relatório síntese. Brasília, 2003.

Exame Nacional de Desempenho dos Estudantes: Enade. Brasília, 2005a.

Censo da educação superior: sinopse. Brasília, 2005b. Disponível em:

<http://portal.inep.gov.br/web/censo-da-educacao-superior>. Acesso em: 20 abr. 2010.

. Exame Nacional de Desempenho dos Estudantes: ENADE. Brasília, 2008a.

. Resumo técnico do censo da educação superior. Brasília, 2008b.

LEITÃO, T. et al. Uma análise acerca do boicote dos estudantes aos exames de avaliação da educação superior. Revista Brasileira de Educação, Rio de Janeiro, v. 15, n. 43, p. 21-44, 2010.

LIBÂNEO, J. C. Didática. São Paulo: Cortez, 1999.

PAIVA, G.S. Avaliação do desempenho dos estudantes da educação superior: a questão da equidade e obrigatoriedade no Provão e ENADE. Ensaio: avaliação e políticas públicas em educação, Rio de Janeiro, v. 16, n. 58, p. 31-46, 2008.

RANIERI, N. Educação superior, direito e Estado na lei de diretrizes e bases. São Paulo: Edusp, 2000.

RIBEIRO, V. K. Abordagem dos conteúdos de biologia celular em cursos de ciências biológicas e sua relação com as avaliações nacionais. 2011. 445 f. Tese (Doutorado em Biologia Celular e Estrutural) - Instituto de Biologia, Universidade Estadual de Campinas, Campinas, 2011.

RISTOFF, D. I. Algumas definições de avaliação. In: DIAS SOBRINHO, J.; RISTOFF, D. I. (Org.). Avaliação e compromisso público. Florianópolis: Insular, 2003. p.21-34.

TOMITA, N. Y. De história natural a ciências biológicas. Ciência e Cultura, São Paulo, v. 42 , n. $10 / 11 / 12$, p. $1172-1177,1990$.

VERHINE, R. E.; DANTAS, L. M. V.; SOARES, J. F. Do Provão ao Enade: uma análise comparativa dos exames nacionais utilizados no ensino superior brasileiro. Ensaio: avaliação e políticas públicas em educação, Rio de Janeiro, v. 14, n. 52, p. 291-310, 2006.

Artigo recebido em 05/09/12. Aceito em 19/01/13. 